\title{
EFEITO DE DIFERENTES SUBSTRATOS E CONDIÇŌES AMBIENTAIS NA GERMINAÇÃO DE SEMENTES DE EUTERPE EDULIS MART. E GEONOMA SCHOTTIANA MART.
}

\author{
Francismar Francisco Alves Aguiar'
}

RESUMO - Duas espécies da família Palmae: Euterpe edulis Mart. (palmiteiro) e Geonoma schottiana Mart. (guaricanga), ambas com potencial ornamental e em vias de extinção, estão sendo estudadas no Instituto de Botânica de São Paulo, quanto à germinação de suas sementes. Testes de germinação foram realizados em diferentes condiçōes ambientais (casa de vegetação e laboratório) e substratos (terra vegetal, areia, esfagno natural, esfagno seco moído e vermiculita). O efeito dos substratos e dos ambientes na germinação das sementes, foi avaliado através da porcentagem de germinação e velocidade de germinação (V.G.). Considerando-se os resultados obtidos, pode-se concluir que o melhor substrato para germinação de Euterpe edulis Mart. em casa de vegetação foi o esfagno natural. Já em condições controlada $\left(25^{\circ} \mathrm{C}\right.$ e fotoperíodo de 12 horas), o melhor substrato para germinação das duas espécies investigadas foi a vermiculita.

Palavras-chave: Sementes, Substratos, Ambientes, Germinação, Palmeiras, Mata Atlântica.

ABSTRACT - (Effects of different substrates and environmental conditions upon the germination of seeds of Euterpe edulis Mart. and Geonoma schottiana Mart.). Two species of the family Palmae: Euterpe edulis Mart. (palmiteiro) and Geonoma schottiana Mart. (guaricanga), both potentially ornamental and threatened by extinction, are being studied for seed germination. Tests were undertaken in different environmental conditions (greenhouse and laboratory) and substrates (organic soil, sand, green sphagnum moss, dry, ground spahgnum and vermiculite). The effect of environmental conditions and substrates upon the germination of seeds was evaluated by the percentage germination and rate of germination (V.G.) percentages. The best substrate for the germination of Euterpe edulis Mart., in greenhouse was green sphagnum moss. Under controlled conditions $\left(25^{\circ} \mathrm{C}\right.$ and 12 hours photoperiod), the best substrate for germination of both species investigated was vermiculite.

Key-words: Seeds, Environments, Germination, Palms.

1 - Instituto de Botânica - Secretaria do Meio ambiente - Caixa Postal 4005 - 01051 São Paulo, SP. Projeto "Mata Atlântica", desenvolvido com auxílio financeiro do CNPq. 


\section{Introdução}

Embora o Brasil conte com um grande potencial de palmeiras nativas que poderiam ser utilizadas na ornamentação, atualmente são mais difundidas as palmeiras exóticas, em detrimento da potencialidade das espécies nativas.

O Estado de São Paulo originalmente tinha $82 \%$ de sua área coberta por florestas. Hoje, essa área está reduzida a cerca de 5\%. E a estimativa para o ano 2000 é de apenas 3\% (Victor, 1975).

O desmatamento dessas regiōes tem sido feito de maneira extrativista e irracional. Dentre as diversas espécies vegetais vítimas do extrativismo, destacam-se o palmito (Euterpe edulis Mart.) e palmeiras do gênero Geonoma, que são intensamente comercializadas, a primeira para consumo do broto apical "in natura" em saladas, pastelarias ou indústrias de conservas, as do gênero Geonoma para firmas de decoração de interiores e floriculturas que utilizam suas folhas como arranjos florais.

Conforme Reitz (1974), “a espécie Geonoma schottiana Mart. (guaricanga-de-folha-miúda) é uma palmeira de 2 até $5 \mathrm{~m}$ de altura, $3 \mathrm{~cm}$ de diâmetro, anelado, anéis salientes. Tem área de dispersão desde o Piauí até Santa Catarina e Rio Grande do Sul. É planta ornamental graças a elegância de suas folhas, que secadas à sombra são produtos de exportação para a Europa e outros países. Os pecíolos rachados servem para trançados (cestos, balaios, etc.). A folha inteira é largamente usada em cobertura de ranchos, casas rústicas, cabanas de hotéis de luxo, etc. Espécie característica e exclusiva da mata pluvial da encosta atlântica do sul do Brasil".

Até 1972 Santos (SP) era o principal porto exportador de palmito em conserva da espécie Euterpe edulis. A partir de 1973 houve uma reversão nessa situação, passando à Belém, o principal porto exportador do produto da espécie Euterpe oleracea, atingindo em 1984 a dominar $87 \%$ do volume, contra apenas 4\% de Santos (Yamazoe et alii (1986).

Segundo BOVI et al. (1987) o palmiteiro é sem dúvida uma das plantas comercialmente explorada que pode ser cultivada em uma floresta nativa, em harmonia com seu ecossistema.

A espécie E.edulis Mart., foi dentre muitas utilizadas no plantio de recomposição da vegetação da serra do Mar em Cubatão. Além do palmiteiro, foram também relacionadas como passíveis de utilização para recomposição da vegetação da Serra do Mar, as palmeiras Geonoma gamiova Barb. Rodr., Geonoma schottiana Mart., dentre outras (Instituto de Botânica, Série Pesquisa, Abr, 1989).

Yocun (1964) e Bovi \& Cardoso (1976) citaram que "a duração de germinação de sementes de palmeiras variam de 1 a 6 meses, sendo que em alguns casos podem variar de 18 meses a 4 anos".

Essa variação depende de espécies, da tempertura, do substrato e das condições de umidade e aeração. 
Matthes \& Castro (1987) reportanđờ-se sobre o período de germinação requerido pelas palmeiras, afirmam que "para a quase totalidade das espécies, estes dados são ainda escassos”. Segundo os autores, para a espécie Euterpe edulis são necessários 14 e 88 dias para início do processo de germinação; já a espécie Geonoma schottiana, requer 174 dias para iniciar a germinação. Essas diferenças quanto ao número de dias necessários à germinação de sementes de uma mesma espécie, também foram anotadas por Loomis (1958) e Koebernik (1971)"'.

Bovi \& Cardoso (1976) testaram diversos pré-tratamentos e seus efeitos na germinação de sementes do açaizeiro (Euterpe oleracea Mart.). O despolpamento do fruto foi o tratamento mais eficiente para as sementes do açaí.

Segundo Pereira Pinto et al (1986), "entre as palmeiras brasileiras está uma fonte inesgotável de recursos paisagísticos. A pidorama brasileira é a mais rica e diversificada do mundo".

Souza (1980), afirma que: "No Brasil permanece em aberto uma quantidade considerável de trabalhos visando melhor conhecimento das palmeiras, sob todos os pontos de vista, desde a identificação botânica até a sua exploração econômica e emprego paisagístico".

Portanto, estudo de germinação e técnicas de cultivo se faz necessário, visando conhecimento sobre o comportamento dessas espécies e sua difusão como planta ornamental.

\section{Material e Métodos}

\section{Trabalho de Campo:}

1.1. Coleta de material botânico para herbário.

1.2. Seleção de plantas matrizes e etiquetação dessas matrizes para coleta de sementes e observação fenológica.

1.3. Coleta de frutos.

2. Trabalhos de Laboratório:

2.1. Preparo e acondicionamento das sementes.

Uma vez colhido os frutos maduros, foram postos em um balde com água durante três dias, com renovação diária da água. Após esta etapa, procede-se despolpamento, friccionando os frutos com a palma da mão sobre as malhas de uma peneira grossa, sob água corrente. A seguir, as sementes são postas para secar à sombra por um dia, sendo então acondicionadas em recipientes plásticos e colocados em geladeira.

2.2. Testes de Germinação.

Do lote de sementes obtido extraí-se uma primeira amostra para realização do teste imediato de germinação em diferentes substratos e condições. Foram testados os seguintes substratos: Terra Vegetal, Areia, Esfagno Natural, Esfagno Seco-Moído e Vermiculita, em Germinador FANEM a $25^{\circ} \mathrm{C}$ mais ou menos $1^{\circ} \mathrm{C}$, com fotoperíodo de 12 horas e em casa de vegetação com cober- 
tura de vidro transparente.

2.3. Para os testes mensais de germinação com vistas a longevidade das sementes foram realizados no substrato e ambiente mais adequado, revelados no teste anterior (imediato).

As sementes foram distribuídas em caixas Gerbox, utilizando-se 12 sementes por caixa, com 5 repetições por tratamento (substrato). As sementes foram cobertas com uma fina camada do substrato, regadas com água de tornei$\mathrm{ra}$, fechando-se as caixas Gerbox com tampas transparentes e acondicionando-as nos ambientes diversos.

Os experimentos tiveram acompanhamento através de observações periódicas e de regras para manter o substrato sempre úmido. As anotações dos dados observados foram feitas em fichas de acompanhamento dos testes.

As plantas obtidas foram repicadas para recipientes individuais, previamente preparados com substratos para os ensaios de cultivo. Os dados obtidos em percentagem referentes a germinação foram transformados em Arco Seno, para a aplicação de análise de variância. O estudo de comparação entre médias, para todos os tratamentos com análise de variância, foram efetuados através do teste de Tukey.

A germinação foi verificada a cada 7 dias, sendo a velocidade de germinação determinada através do cálculo do tempo médio de germinação de acordo com a fórmula: $\mathrm{VG}=\Sigma \mathrm{nt} / \mathrm{N}$ (Hartmann \& Kester, 1975), onde VG $=$ velocidade de germinação, $\mathrm{n}=$ número de sementes germinadas em um período $\mathrm{t}$ expresso em dias e $\mathrm{N}$ o número total de sementes germinadas. $\mathrm{O}$ delineamento usado foi o inteiramente casualizado.

\section{Resultados e Conclusões}

Os resultados obtidos no experimento realizado com diferentes substratos e condiçōes ambientais na germinação de Euterpe edulis Mart. e Geonoma schottiana Mart. são mostrados nas Figuras 1, 2, e 3.

Em condições de Casa de Vegetação, os substratos para germinação de Euterpe edulis (Figura 1), esfagno natural com $74 \%$ e vermiculita $66 \%$ de germinação, não diferiram estatisticamente entre si. Entretanto, o substrato terra vegetal apresentou comportamento estatisticamente inferior aos anteriores.

Quanto a velocidade de germinação, os tratamentos apresentaram comportamento semelhantes ao teste de porcentagem de germinação.

Já em condiçōes de laboratório, os três substratos testados para a germinação de Euterpe edulis (Figura 2) não apresentaram diferença entre si, tanto em relação a porcentagem de germinação como em relação a velocidade de germinação. 


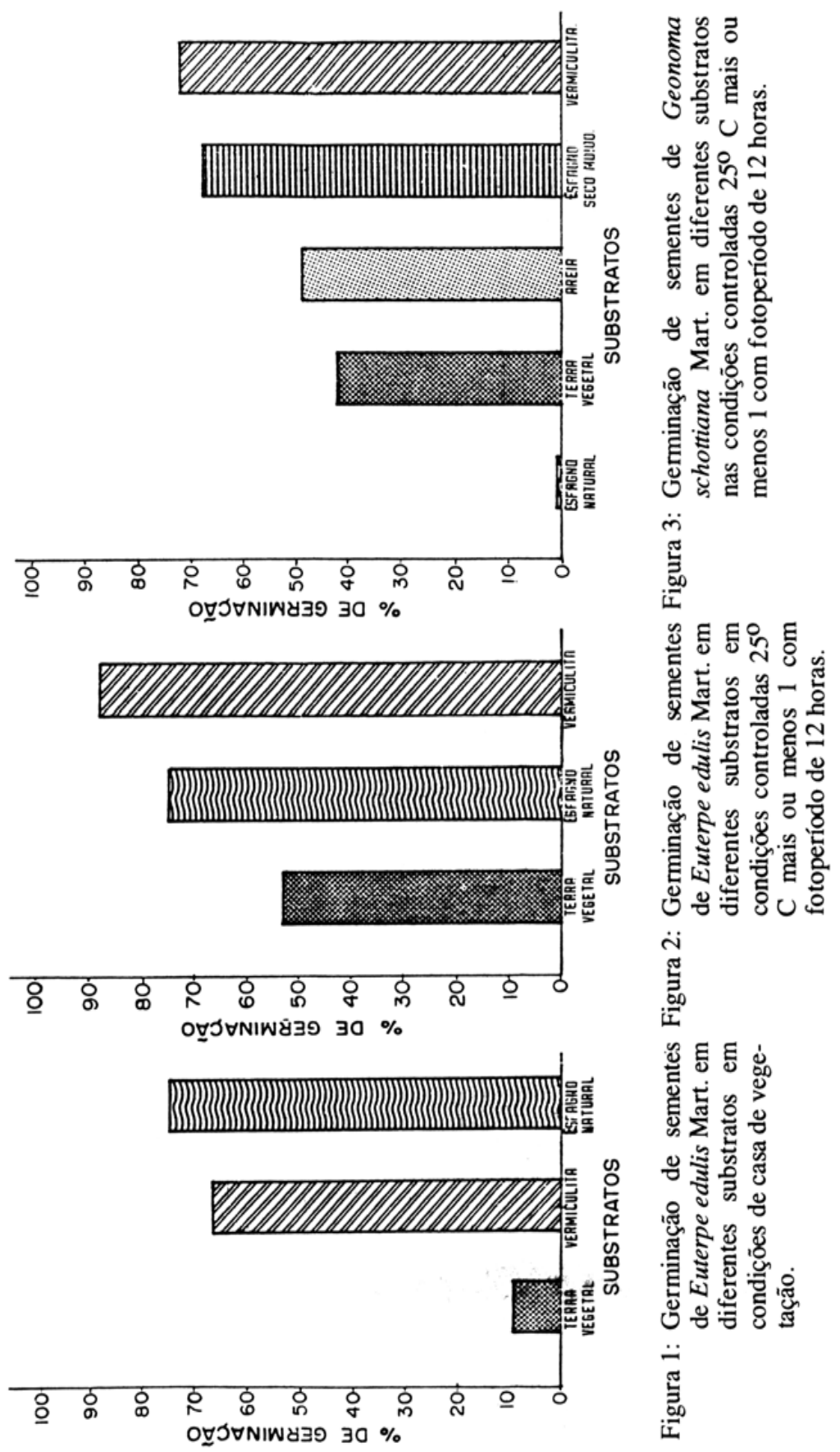


Com referência a porcentagem de germinação de Geonoma schottiana em laboratório (Figura 3), os substratos: Areia, Esfagno-Seco-Moído e Vermiculita, não diferiram entre si, sendo porém superiores a terra vegetal. Entretanto, com relação a velocidade de germinação todos tenham diferidos entre si, com superioridade para esfagno seco-moído.

Bovi \& Cardoso (1976) estudando a germinação de sementes de Euterpe edulis em condições de viveiro, utilizando cinco tratamentos, com uma das parcelas sombreadas com sapé, concluíram que todos os tratamentos da parcela sem cobertura vegetal morta, apresentaram as maiores porcentagens finais de germinação. Os tratamentos 2 e 3 (fruto despolpado e frutos despolpados e escarificado) não diferiram significativamente entre si, com 57 e $54 \%$ de germinação respectivamente, sendo entretanto superiores as demais.

Se compararmos as porcentagens de germinaçäo verificadas por Bovi \& Cardoso (1976), com aquelas obtidas neste experimento, tanto em condiçōes de germinador, com o substrato vermiculita ( $88 \%$ ), como em casa de vegetação, com o substrato esfagno natural $(74 \%)$, verifica-se que as porcentagens de sementes germinadas em ambos os casos, foram superiores aos tratamentos 2 e 3 verificados por Bovi \& Cardoso (1976). Se por outro, compararmos os resultados observados por Bovi \& Cardoso (1975) em que foram utilizados dez tratamentos para germinação de sementes de Euterpe edulis, com os dados obtidos neste experimento, verifica-se que pelo menos dois tratamentos dentre os dez (o 5: sementes escarificadas a $20-40^{\circ} \mathrm{C}$ e o 6 : sementes escarificadas a $35^{\circ} \mathrm{C}$ ) apresentaram resultados semelhantes, com $72 \%$ e $76 \%$ de germinação respectivamente.

Matthes \& Castro (1987) reportando-se sobre o período de germinação requerido pelas palmeiras, citam para a Euterpe edulis Mart., 14 a 88 dias (duas amostras diferentes). Já para Geonoma schottiana Mart., afirmam que são necessários 174 dias para início da germinação. Segundo ainda os mesmos autores, diferenças quanto ao número de dias necessários à germinação de sementes de uma mesma espécie, também foram observados por Loomis (1958) e Koebernik (1971).

Neste trabalho, em condição de cada de vegetação, verificou-se o início da germinação de sementes de Euterpe edulis Mart. aos 29 dias após plantio. Já em laboratório (germinador) as sementes iniciaram o processo de germinação após 17 dias da instalação. Quanto à Geonoma schottiana Mart., em laboratório, o período requerido para início de germinação foi de 206 dias. As diferenças entre os resultados observados por Bovi \& Cardoso (1976) e Matthes \& Castro (1987) e os obtidos neste trabalho, provavelmente sejam devido às condições ambientais e de substratos.

De acordo com os resultados obtidos nas condições deste experimento, ficaram evidenciados que os substratos vermiculita em condições de laboratório e esfagno natural em casa de vegetação foram superiores aos demais substratos investigados para germinação de sementes de Euterpe edulis Mart. 
e Geonoma schottiana Mart.

\section{Referências bibliográficas}

BOVI, M.L.A. \& M.G. CARDOSO 1976. Germinação de sementes de palmiteiro (Euterpe edulis Mart.) 2. Bragantia, Campinas, 35:23 - 9. (nota 6).

BOVI, M.L.A.; L.A. SAES; M. CARDOSO \& J. CIONE 1987. Densidade de plantio de palmiteiro em regime de sombreamento permanente(1). Bragantia, Campinas, 46(2):329-341.

HARTMANN, H.T. \& D.E. KESTER 1975. Plant Propagation: principles and practies. 3. ed. Prentice Hall Inc. New Jersey.

INSTITUTO DE BOTÂNICA. 1989. Recomposição da vegetação da Serra do Mar em Cubatão, São Paulo - Brasil, Instituto de Botânica. Vera Lúcia Ramos Bononi (Coordenadora) Abr. p.68 ilus. (Série Pesquisa 1).

KOEBERNIK, H.F. 1971. Germination of palm seed. Principes. 15(4): 134-137.

LOOMIS, H.P. 1958. The preparation and germination of palm seed. Principes. 2(3):98-102.

MATTHES, L.A.F. \& C.E.F. CASTRO, 1987. Germinação de sementes de palmeiras. O Agronômico Campinas, SP. 39(3), p.267-277.

PEREIRA PINTO, G.C.; H.P. BAUTISTA \& J.D.C.A. FERREIRA 1986. Introdução e utilização de plantas nativas em jardinocultura. In: Anais Congresso Brasileiro de Floricultura e Plantas Ornamentais.

3. Salvador, São Paulo, Instituto de Botânica, Campinas, Fundação Cargil, p.231-250.

REITZ, P.R. 1974. Palmeiras. Flora Ilustrada Catarinense. $1^{\text {a }}$ parte: as plantas. Itajaí. (Palm.)1-189.

SOUZA, H.M. 1980. Sementes de Palmeiras. O Estado de São Paulo. São Paulo, 6 fev. Suplemento Agrícola, p.5.

VICTOR, N.N.N. 1975. A devastação florestal. Sociedade Brasileira de Silvicultura, São Paulo.

YAMAZOE, G.; A.C. DIAS \& B.V. MOURA NETTO 1986. Comportamento de Euterpe edulis Mart. nas condições edafoclimáticas de Sete Barras (SP). Boletim Técnico. Instituto Florestal, São Paulo, 40-a (1):123-132.

YOCUN, H.G. 1964. Factors affecting the germination of palm seeds. The American Horticultural Magazine. 43(2):104-6, Abr. 